\title{
National Survey of Pharmacy Leadership at Ministry of Health in Saudi Arabia: Working Environment
}

\author{
Yousef Ahmed Alomi" ${ }^{* 1}$, Modhi Abdulmohsen Albaz ${ }^{2}$, Wejdan Fawzan AlMuhraj², Mashael Yasser AlKharji ${ }^{2}$, \\ Norah Rushud Alshuraym² \\ ${ }^{1}$ The Past General Manager of General Administration of Pharmaceutical Care and Head, National Clinical pharmacy, and \\ pharmacy practice and Pharmacy $R$ and D Administration, Ministry of Health, Riyadh, KSA. \\ ${ }^{2}$ Clinical Pharmacy Staff, General Administration of Pharmaceutical Care, Ministry of Health, Riyadh 11392, SAUDI ARABIA.
}

\section{Received: 13 December 2017; \\ Accepted: 28 February 2018 *Correspondence to: \\ Dr. Yousef Ahmed Alomi,} The Past General Manager of General Administration of Pharmaceutical Care Head, National Clinical pharmacy, and pharmacy practice Head, Pharmacy $R$ and $D$ Administration Ministry of Health, P.O.BOX 100, Riyadh 11392, Riyadh, SAUDI ARABIA. Riyadh, Saudi Arabia.

Email: yalomi@gmail.com Copyright: (C) the author(s),publisher and licensee Indian Academy of Pharmacists. This is an open-access article distributed under the terms of the Creative Commons Attribution Non-Commercial License, which permits unrestricted non-commercial use, distribution, and reproduction in any medium, provided the original work is properly cited.

\begin{abstract}
Objective: To explore the national survey of pharmacy leadership at the Ministry of Health with emphasis on pharmacy Working Environment. Methods: It is a ninety days cross-sectional national survey of pharmacy leadership practice at Ministry of Health. The survey modified from self-assessment of 360 leadership and with pharmacy leadership literature. The electronic format of the survey through the survey monkey system and distributed through emails. All analysis is done through the survey monkey system. The survey divided into several parts for analysis, and discussion. Part one: practice management, part two: planning and organizations, part three: communications strategies, part four: problem-solving and decision making, part five: performances management, part six; working environment, and part seven: professional development. The study explored the part number six: National Survey of Pharmacy leadership: Working Environment. Results: The survey distributed to one hundred hospitals, the response rate, was forty-two hospitals (42\%) with seventy-pharmacy leaders. The gender distribution of responders was Male $43(63.24 \%)$ and female 25 (36.76\%) while the nationality was Saudi 69 (98.57\%) and non-Saudi $1(1.43 \%)$. The majority of pharmacy leadership described the current environment as work culture A 24 (38.1\%) and work culture C 23 (36.5\%). The most of them preferred work culture B 20 (31.25\%) and Work culture A 19 (29.69\%). The average score Cultural Awareness skills were 2.48 (82.65\%) with the highest score was Full respect for people who are not sharing the same region 2.73 (90.99\%). The majority of pharmacy leaders agreed the higher Management within the organization recognizes strong job performance 31 (46.27\%), the Employees proactively identify future challenges and opportunities $33(53.23 \%)$, and Employees in my organization willingly accept change $31(47.69 \%)$. Most of the pharmacy leaders (70\%) though that is the maximum time should become pharmacy leader at his or her position four to five years. Conclusion: The pharmacy leaders had some challenges with workplace environment. Targeting to review pharmacy workplace and implement the new model of the culture environment is required. Also, further with another a detail investigation of pharmacy workplace environment is highly recommended at healthcare organizations in Saudi Arabia.
\end{abstract}

Key word: Pharmacy leadership, Working environment, Ministry of health, Saudi arabia.

\section{INTRODUCTION}

The American Society of Heath-System pharmacist and pharmacy societies provide to the pharmacy leaders very comprehensive educational courses, annual conferences of pharmacy leaders and several publications through the Journal American Journal of Health-System Pharmacist. ${ }^{[1-4]}$ Most of them discussed the tools and skills of pharmacy leaders including the working environment. Few studies investigated the workplace environment with pharmacy leadership. ${ }^{[5-6]}$ It very hard to find an investigation of pharmacy leadership including working environment in Saudi Arabia or Gulf and Middle East counties. The objective of the study to explore the national survey of pharmacy leadership with emphasis on the working environment.

\section{METHODS}

It is a ninety days cross-sectional national survey of pharmacy leadership practice at $\mathrm{MOH}$ hospitals. The survey modified from self-assessment of 360 leadership and with pharmacy leadership literature. It consisted of a demographic section, leadership pathway, and fifty-three leadership questions. It contained selected eighteen leadership skills of 360 leadership self-assessment. ${ }^{[7]}$ Of The leadership skills included Achievement, Goals, Flexibility, Feedback, Excellence, Empowering Others, Emotional Intelligence, Decision Making, Developing Others, Cultural Awareness, Continual Improvement, Communication Skills, Coworker Development, Leading the Change Needed, Attitude, Analytical, Administrative Skill, and Action. The questions consisted of open and closed questions. The 5-points or 3-point Likert response scale system used. This survey distributed to all leadership at $\mathrm{MOH}$ hospital pharmacies in Kingdom of Saudi Arabia. It included general director of pharmacy at $\mathrm{MOH}$ and regions, the directors of pharmacy and supervisor at $\mathrm{MOH}$ hospital pharmacies. The electronic format of the survey through the survey monkey system and distributed through emails. A reminder e-mail containing a link to the website forwarded two weeks after. All analysis is done through the survey monkey system. The survey divided into for several parts for analysis, and discussion. Part one: practice management, part two: planning and organizations, part three: communications strategies, part four: problem-solving and decision making, part five: performances management, part six; working environment, and 
part seven: professional development. The study explored the part number one; National Survey of Pharmacy leadership: Working Environment.

\section{RESULTS}

The survey distributed to the one hundred hospitals, the response rate, was forty-two hospitals $(42 \%)$ with seventy-pharmacy leaders. Most of the hospital bed size (200-299) was 16 (24.24\%) followed by nine (13.64\%) bed size (300-399) and eight the (12\%) more than bed size $(=$ or $>600)$. The number of hospitals accredited by the Saudi Central Board of Hospitals Accreditation (CIBAHI) was $36(76.60 \%)$ while 22 hospitals $(46.81 \%)$ accredited by USA International Joint Commission and CIBAHI and
$11(23.40 \%)$ accredited by the Saudi Commission of Healthcare specialties. The gender distribution of responders was Male 43 (63.24\%) and female $25(36.76 \%)$ while the nationality was Saudi $69(98.57 \%)$ and non-Saudi $1(1.43 \%)$. Most responders were in the age range (25-34) years, $30(55.12 \%)$ and (35-44 years) 26 (38.24\%). The academic qualifications of responders were BSc. Pharm 44 (64.71\%) followed by Mater degree $9(13.24 \%)$ and Diploma Pharmacy 7 (10.29\%). Of those, only 10 (14.93\%) completed a residency program in pharmacy administrations, and four $(4.16 \%)$ had completed board of pharmaceutical specialties. Most responders worked as a supervisor of the unit at hospital pharmacy 33 (50\%) or director of pharmacy $24(36.36 \%)$. Of those they had experienced as pharmacist more than ten years $33(47.14 \%)$ and had administrative work one to three years'

\section{Table 1: Demographic information of pharmacy leaders.}

\begin{tabular}{|c|c|c|c|c|c|}
\hline Gender & Response N & Response \% & Complete pharmacy residency & Response $\mathbf{N}$ & Response \% \\
\hline Male & 43 & $63.24 \%$ & Yes & 10 & $14.93 \%$ \\
\hline Female & 25 & $36.76 \%$ & No & 57 & $85.07 \%$ \\
\hline Answered question & 68 & & Answered question & 67 & \\
\hline Skipped question & 2 & & Skipped question & 3 & \\
\hline Nationality & Response N & Response \% & Do you have Board of Pharmaceutical Specialty & Response N & Response \% \\
\hline Saudi & 69 & $98.57 \%$ & Board Certified Ambulatory Care Pharmacist & 1 & $1.54 \%$ \\
\hline Non- Saudi & 1 & $1.43 \%$ & Board Certified Critical Care Pharmacist & 1 & $1.54 \%$ \\
\hline Answered question & 70 & & Board Certified Pharmacotherapy Specialists & 2 & $3.08 \%$ \\
\hline Skipped question & 0 & & Non & 62 & $95.38 \%$ \\
\hline \multicolumn{3}{|c|}{ Academic Qualification (s } & Answered question & 65 & \\
\hline 18 to 24 & 0 & $0.00 \%$ & Skipped question & 5 & \\
\hline 25 to 34 & 30 & $44.12 \%$ & Total years of current position & Response N & Response \% \\
\hline 35 to 44 & 26 & $38.24 \%$ & General Manager of Pharmaceutical care & 5 & $7.58 \%$ \\
\hline 45 to 54 & 10 & $14.71 \%$ & Manager of Pharmaceutical care at region & 1 & $1.52 \%$ \\
\hline 55 to 64 & 1 & $1.47 \%$ & Director of Hospital pharmacy & 24 & $36.36 \%$ \\
\hline 65 to 74 & 1 & $1.47 \%$ & Supervisor of pharmacy units & 33 & $50.00 \%$ \\
\hline 75 or older & 0 & $0.00 \%$ & Director of Primary care center pharmacy & 3 & $4.55 \%$ \\
\hline Answered question & 68 & & Answered question & 66 & \\
\hline Skipped question & 2 & & Skipped question & 4 & \\
\hline \multicolumn{3}{|c|}{ Academic Qualification (s } & Total years worked as a Pharmacist & Response N & Response \% \\
\hline Diploma Pharmacy & 7 & $10.29 \%$ & $<3$ & 9 & $13.24 \%$ \\
\hline Bsc. Pharm & 44 & $64.71 \%$ & $3-5$ & 13 & $19.12 \%$ \\
\hline M.S & 9 & $13.24 \%$ & $6-10$ & 13 & $19.12 \%$ \\
\hline Msc. Clinical Pharmacy & 4 & $5.88 \%$ & $11-15$ & 14 & $20.59 \%$ \\
\hline Pharm.D. & 11 & $16.18 \%$ & $>15$ & 19 & $27.94 \%$ \\
\hline Ph.D & 0 & $0.00 \%$ & Answered question & 68 & \\
\hline MBA & 4 & $5.88 \%$ & Skipped question & 2 & \\
\hline Pharmacy Residency (R1) & 2 & $2.94 \%$ & Years of experience in administrative work & Response $\mathbf{N}$ & Response \% \\
\hline Pharmacy Residency (R2) & 2 & $2.94 \%$ & Less than one year & 10 & $14.29 \%$ \\
\hline Fellowship & 1 & $1.47 \%$ & $1-3$ years & 18 & $25.71 \%$ \\
\hline Other (please specify) & 6 & $8.82 \%$ & $4-5$ years & 13 & $18.57 \%$ \\
\hline Answered question & 68 & & $6-10$ & 14 & $20.00 \%$ \\
\hline \multirow[t]{3}{*}{ Skipped question } & 2 & & More than ten years & 15 & $21.43 \%$ \\
\hline & & & Answered question & 70 & $14.29 \%$ \\
\hline & & & Skipped question & 0 & \\
\hline
\end{tabular}


experience1 8 (25.71\%) and more than ten years were $15(21.43 \%)$ as explored in Table 1 and Table 2. The majority of pharmacy leadership described the current environment as work culture A $24(38.1 \%)$ and work culture C 23 (36.5\%). The most of them preferred work culture B $20(31.25 \%)$ and Work culture A 19 (29.69\%) as explored in Table 3.The average score Cultural Awareness skills were 2.48 (82.65\%) with the highest score was Full respect for people who are not sharing the same region $2.73(90.99 \%)$, and the lowest score was I am sensitive to the different cultural backgrounds $2.16(71.99 \%)$ as explored in Table 4 . The majority of pharmacy leaders agreed the higher Management within the organization recognizes strong job performance $31(46.27 \%)$, the Employees proactively identify future

\begin{tabular}{|l|l|l|}
\hline \multicolumn{3}{|l|}{ Table 2: Demographic hospital information. } \\
\hline Number of beds at hospital & Response N & Response \% \\
\hline$<50$ & 6 & $9.09 \%$ \\
\hline $50-99$ & 5 & $7.58 \%$ \\
\hline $100-199$ & 7 & $10.61 \%$ \\
\hline $200-299$ & 16 & $24.24 \%$ \\
\hline $300-399$ & 9 & $13.64 \%$ \\
\hline $400-599$ & 4 & $6.06 \%$ \\
\hline More than or equal 600 & 8 & $12.12 \%$ \\
\hline Medical City & 7 & $10.61 \%$ \\
\hline $\begin{array}{l}\text { Regional Drug Information Centers at } \\
\text { General Health Affairs Directorate) }\end{array}$ & 4 & $6.06 \%$ \\
\hline Answered question: 70 and skipped : 0 & \multicolumn{2}{|l}{} \\
\hline The hospital accreditation & Response & $\begin{array}{l}\text { Response } \\
\text { Count }\end{array}$ \\
\hline CIBAHI & 36 & $76.60 \%$ \\
\hline $\begin{array}{l}\text { Saudi Commission of Healthcare } \\
\text { specialties }\end{array}$ & 11 & $23.40 \%$ \\
\hline JCI & 22 & $46.81 \%$ \\
\hline Canada & 2 & $4.26 \%$ \\
\hline ASHP & 0 & $0.0 \%$ \\
\hline ACCP & 1 & $5.0 \%$ \\
\hline Non & 4 & $20.0 \%$ \\
\hline Answered question: 47 and skipped question 23 & \\
\hline & & \\
\hline
\end{tabular}

challenges and opportunities 33 (53.23\%), and Employees in my organization willingly accept change $31(47.69 \%)$. Most of the pharmacy leaders $(70 \%)$ though that is the maximum time should become pharmacy leader at his or her position four to five years as explored in Table 5 .

\section{DISCUSSION}

The implementation of pharmacy strategic planning need leaders from Pharmacy to organize that is one. The successful plan needs very competent pharmacy leaders. Despite the presenting of an excellent leader, the demand for assistance leaders and working environment is necessary. The working environment involved several factors, for instance, the place of working with, a team of the work, higher administration, the communication and relationships among pharmacy staff. The fourth general of pharmacy strategic goal stated to create the working culture and environment. ${ }^{[8]}$ The pharmacy administration Established several tools for working culture or environment including the pharmacist job satisfaction done annually by all pharmacy staff and reported to pharmacy administration. ${ }^{[9]}$ The design of working place with requirements equipment, medical and pharmaceutical furniture, the shape of the place, and included with manual of pharmacy design and equipment described each pharmacy units and development. To make the pharmacy staff living and working in excellence environment place. Another program released to the created favorable working environment was the patient satisfaction of the pharmacy services. ${ }^{[10-11]}$ The program will encourage the pharmacist to communicate efficiently with all patients and provide best the services. Also, the pharmacy administration increase number of pharmacy workforce to facilitate the work very efficiently with proper environments. ${ }^{[12-13]}$ All those factors should organize and lead through pharmacy leaders. The investigator tried to measure the pharmacyworking environment through a national survey of pharmacy leadership at a healthcare organization in Kingdom of Saudi Arabia. The findings showed the majority of pharmacy leadership between two environments at the current situation with the open and friendly environment and worked as a team without policy and procedure or the second environment with policy and procedures and very structure places and organization. That's reflected the pharmacy practice either open or very restricted. The first one either old leader or had much experience and leadership through communication and other one new and do not had much experience and follow policy and fried to got mistakes. However, the most the leaders to be category B which leadership industry or the very open environment. That's mean most wish to be accurate and appropriate leaders, but maybe several factors stop the process of pharmacy leadership, for instance, the education and training

\section{Table 3: Work environment.}

\begin{tabular}{|c|c|c|c|c|c|c|c|c|c|}
\hline \multirow{2}{*}{$\begin{array}{l}\text { Answer Options } \\
\text { Select one of the work culture that best describes your current work environment: }\end{array}$} & \multicolumn{2}{|c|}{$\begin{array}{c}\text { Work } \\
\text { culture A }\end{array}$} & \multicolumn{2}{|c|}{$\begin{array}{c}\text { Work } \\
\text { culture B }\end{array}$} & \multicolumn{2}{|c|}{$\begin{array}{c}\text { Work } \\
\text { culture C }\end{array}$} & \multicolumn{2}{|c|}{$\begin{array}{c}\text { Work } \\
\text { culture D }\end{array}$} & \multirow{2}{*}{$\begin{array}{c}\text { Response N } \\
63\end{array}$} \\
\hline & 24 & $38.10 \%$ & 7 & $11.11 \%$ & 23 & $36.51 \%$ & 9 & $14.29 \%$ & \\
\hline $\begin{array}{l}\text { Of the work cultures described above, which ONE culture would you PREFER to } \\
\text { work within? }\end{array}$ & 19 & $29.69 \%$ & 20 & $31.25 \%$ & 17 & $26.56 \%$ & 8 & $12.50 \%$ & 64 \\
\hline $\begin{array}{l}\text { Work culture A } \\
\text { An open and friendly place to work where people share a lot of themselves. } \\
\text { Leaders are considered to be mentors or even parental figures. } \\
\text { Group loyalty and sense of tradition are strong. } \\
\text { There is an emphasis on the long-term benefits of human resources development, } \\
\text { and great importance is given to group cohesion. } \\
\text { There is a high concern for people. } \\
\text { The organization places a premium on teamwork, participation, and consensus. }\end{array}$ & \multicolumn{9}{|c|}{$\begin{array}{l}\text { Work culture C } \\
\text { A highly structured and formal place to work. } \\
\text { Rules and procedures govern behavior. } \\
\text { Leaders strive to be good coordinators and organizers who are efficiency-minded. } \\
\text { Maintaining a smooth-running organization is most critical. } \\
\text { Formal policies are what hold the group together. } \\
\text { Stability, performance, and efficient operations are the long-term goals }\end{array}$} \\
\hline $\begin{array}{l}\text { Work culture B } \\
\text { A dynamic, entrepreneurial, and creative place to work. Employees and leaders } \\
\text { embrace innovation and risk-taking. } \\
\text { A commitment to experimentation and thinking differently are what unify the } \\
\text { organization. } \\
\text { The long-term emphasis is on growth and acquiring new resources. } \\
\text { Being an industry leader is essential. } \\
\text { Individual initiative and freedom are encouraged. }\end{array}$ & \multicolumn{9}{|c|}{$\begin{array}{l}\text { Work culture D } \\
\text { A results-driven organization focused on job completion. } \\
\text { People are competitive and goal-oriented. } \\
\text { Leaders are demanding, hard-driving, and productive. } \\
\text { The emphasis on winning unifies the organization. } \\
\text { Reputation and success are common concerns. } \\
\text { Long-term focus is on competition and achievement of measurable goals and targets. }\end{array}$} \\
\hline
\end{tabular}


Table 4: Cultural Awareness.

\begin{tabular}{|l|l|c|c|c|c|c|c|c|c|}
\hline & Answer Options & \multicolumn{2}{|c|}{ Never } & \multicolumn{2}{|c|}{ Sometimes } & \multicolumn{2}{c|}{ Always } & Average & Response N \\
\hline 1 & Values the opinions of diverse groups and individual. & 2 & $3.17 \%$ & 24 & $38.10 \%$ & 37 & $58.73 \%$ & 2.56 & 63 \\
\hline 2 & Encourage a diversity work environment. & 1 & $1.59 \%$ & 30 & $47.62 \%$ & 32 & $50.79 \%$ & 2.49 & 63 \\
\hline 3 & I am sensitive to the different cultural backgrounds. & 9 & $14.29 \%$ & 35 & $55.56 \%$ & 19 & $30.16 \%$ & 2.16 & 63 \\
\hline 4 & Full respect for people who are not sharing the same region. & 0 & $0.00 \%$ & 17 & $26.56 \%$ & 47 & $73.44 \%$ & 2.73 & 64 \\
\hline
\end{tabular}

\section{Table 5: Concept of working environment.}

\begin{tabular}{|c|c|c|c|c|c|c|c|c|c|c|c|c|}
\hline \multirow[b]{2}{*}{1} & \multirow{2}{*}{$\begin{array}{l}\text { Answer Options } \\
\text { The Management within my organization recognizes strong job } \\
\text { performance. }\end{array}$} & \multicolumn{2}{|c|}{5} & \multicolumn{2}{|c|}{4} & \multicolumn{2}{|c|}{3} & \multicolumn{2}{|r|}{2} & \multicolumn{2}{|r|}{1} & \multirow{2}{*}{$\begin{array}{c}\text { Response N } \\
67\end{array}$} \\
\hline & & 6 & $8.96 \%$ & 31 & $46.27 \%$ & 19 & $28.36 \%$ & 7 & $10.45 \%$ & 4 & $5.97 \%$ & \\
\hline 2 & $\begin{array}{l}\text { The Employees proactively identify future challenges and } \\
\text { opportunities. }\end{array}$ & 3 & $4.84 \%$ & 33 & $53.23 \%$ & 17 & $27.42 \%$ & 6 & $9.68 \%$ & 3 & $4.84 \%$ & 62 \\
\hline 3 & The Employees in my organization willingly accept change. & 5 & $7.69 \%$ & 31 & $47.69 \%$ & 17 & $26.15 \%$ & 10 & $15.38 \%$ & 2 & $3.08 \%$ & 65 \\
\hline 4 & The maximum time should pharmacy leader at his position & 29 & $41.43 \%$ & 20 & $28.57 \%$ & 11 & $15.71 \%$ & 9 & $12.86 \%$ & 1 & $1.43 \%$ & 70 \\
\hline
\end{tabular}

pharmacy leaders. Other wishes keep as the same situation because they are old age and do not need and building up new leaders. The average score Cultural Awareness skills were acceptable with excellent respect environment of other region, but they face difficult background culture to dissolve the pharmacy staff in the environment. That's related to low experience background of pharmacy leaders to communicate very effectively and efficiently with Pharmacy staff to dissolve all barriers between them. The findings of the concept of the working environment of pharmacy leaders are excellent including the higher administration recognized their works, they had pleasant staff with proactive and ready for challenges and willing to change and accepted the new changes. All previous concepts encourage the pharmacy leaders to work very effectively and efficiently and improve pharmaceutical services and expand the pharmaceutical care concept to cover all patient-related drug therapy situations. Most of the leaders wish to work at his or her position four or five years as maximum time only. That's because the pharmacy leaders had very workforce without the support of training and education for leadership and without incentives to encourage the pharmacist to stay in their positions. It hard to compare the previous finding with other studies because of the literature was review papers or not in-depth detail information. ${ }^{[5]}$ Maybe the study is the first study-wide world or Saudi Arabia and Gulf or Middle East countries discussed the pharmacy leaders with the workplace environment. The pharmacy leaders had environment discrepancies with the right staff environment. However, pharmacy leaders wish to change their position within a short period because of missed of preposition leadership preparation, high workload performances, and without any benefits from the positions at the Ministry of Health organization in Kingdom of Saudi Arabia.

\section{CONCLUSION}

The working environment of pharmacy leaders is not acceptable generally. However, the pharmacy staff had created a good culture and workplace environment inside. Targeting of education and training of pharmacy readers to change the environment is highly recommended at $\mathrm{MOH}$ organization in Kingdom of Saudi Arabia.

\section{CONFLICT OF INTEREST}

Author declares no conflict of interest.

\section{ABBREVIATION USED}

KSA: Kingdom of Saudi Arabia, MOH: Ministry of Health.

\section{REFERENCES}

1. Zilz DA, Woodward BW, Thielke TS, Shane RR, Scott B. Leadership skills for a high-performance. Am J Heal Pharm. 2004;61:2562-74.

2. Zellmer WA. Pharmacy Vision and Leadership : Revisiting the Fundamentals. Pharmacotherapy. 2008;28(12):1437.

3. Khan MU, Hassali MA, Ahmad A, Elkalmi RM, Zaidi ST, Dhingra S. Perceptions and practices of community pharmacists towards antimicrobial stewardship in the state of Selangor, Malaysia. PloS one. 2016;11(2):e0149623.

4. Rafi MS, Naqvi SB, Khan MU, Fayyaz M, Ashraf N, Khan MA, et al. Evaluation of Potential Drug-Drug Interactions with Antidepressants in Two Tertiary Care Hospitals. JCDR. 2015;9(7):FC05.

5. Meadows AB, Maine LL, Keyes EK, Pearson K, Finstuen K. Pharmacy executive leadership issues and associated skills, knowledge, and abilities. J Am Pharm Assoc. 2005;45(1):55-62.

6. Toward an Optimal Future: Priorities for Action Research Report 2 Pharmacy Thought Leadership Summit @BULLET Research Report. Canadian Pharmacist Association; 2016.

7. 360 Degree Feedback Items List. Available from: https://hr-survey. com/360FeedbackltemsList.htm

8. Alomi YA, Alghamdi SJ, Alattyh RA. Strategic Plan of General Administration of Pharmaceutical Care at Ministry of Health in Saudi Arabia 2012-2022. J Pharm Pharm Sci. 2015;1(3):1-8.

9. Alomi YA, Al-Ghuraybi B, Aloumi BE, Al-Subaie RS. Communications and Relationship Factors on Pharmacy Carrier Satisfaction Saudi Arabia: Value in Health. 2017;A41-A41.

10. Alomi YA. Patient satisfaction of pharmaceutical care system at Ministry of Health in Saudi Arabia. BAOJ Pharm Sci. 2016;2:19.

11. Alomi YA, Kurdy L, Aljarad Z, Basudan H, Almekwar B, Almahmood S. Patient satisfaction of pharmaceutical care of primary care centers at Ministry of Health in Saudi Arabia. J Pharm Pract Community Med. 2016;2(3):79-87.

12. Alomi YA, Ahmed Alomi Y, Pharm B, Clin Pharm M. A new Guidelines on Hospital Pharmacy Manpower in Saudi Arabia. J Pharm Pract Community Med. 2016;2(2).

13. Alomi YA. Primary Care Center Pharmacy Manpower New Guidelines in Saudi Arabia. J Pharmacol Clin Res. 2016;1(1).

Cite this article as: Alomi YA, Albaz MA, AlMuhraj WF, AlKharji MY, Alshuraym NR. National Survey of Pharmacy Leadership at Ministry of Health in Saudi Arabia: Working Environment. J Pharm Pract Community Med. 2018;4(1s):S88-S91. 